\section{(e) Medical audit}

(14) In recent years, the profession initiated, and has been increasingly involved in, medical audit, particularly through the Royal Medical Colleges and Faculties, and it will continue to be so. A major extension of audit, however, requires good information systems, and the Committee welcomes the Government's recognition that it will be very expensive in terms both of time and of money. It hopes this money will be provided separately and not be taken from existing resources for patient care.

\section{(f) Medical education and research}

(15) The White Paper contains few direct references to medical education or research. However, the major changes that will occur when the White Paper is introduced may have serious deleterious effects on both of these subjects, and very much more detail is required. There is little reassurance that the present support for medical education at all levels in NHS hospitals will be maintained in self-governing hospitals, or that the present facilities-for example, postgraduate medical centres - will continue to be supported. The careful medical manpower planning of hospital posts for postgraduate training may be jeopardised by the need for self-governing hospitals to put their own priorities before those of national requirements.

(16) The JCC questions whether the environment that allows clinical and laboratory research to take place will be maintained or that the new initiative will be allowed to develop when the emphasis is on patient costing rather than care for a community. For example, it doubts whether pain clinics or the new hip replacement operation, both developed by research within the NHS, would have occurred had the new system with its financial imperatives been in place.
(17) The interface between academic and NHS medicine is extremely important to both sides - for undergraduate and postgraduate education, and for both basic and applied medicine; it is essential that the universities and the Royal Medical Colleges and Faculties are given adequate time for full consultation on the complex issues involved.

\section{Consequences of failure}

(18) If this scheme is to be introduced throughout the Service in essentially its present form some thought must be given to the consequences of complete or partial failure. If, as the JCC fears, the information systems are simply not able to provide the accurate information needed within the time-scale suggested, then there will be a prolonged period of great uncertainty and confusion in the Health Service. If inaccurate estimates are substituted for accurate costing information, then hospital planning and the service to the community will be greatly distorted. Furthermore, some of the proposals must mean a substantial increase in organisational costs without any corresponding improvement in patient care. Indeed, unless the total NHS budget is increased substantially, there would be a significant reduction in the resources available for the treatment of patients. It is essential, therefore, that a careful evaluation of pilot studies is undertaken before a more widespread implementation of these proposals. It should be noted that such studies were in fact proposed in Alain Enthoven's monograph on the management of the National Health Service - a document seminal to the White Paper itself. The JCC believes that a failure to test these proposals in practice before their general introduction will inevitably be shown to be a major error of judgement.

March 1989

\title{
Child and Adolescent Psychiatry
}

The College's Child and Adolescent Psychiatry Specialist Section is now inviting submissions for a session of ten minute presentations by senior registrars in child and adolescent psychiatry to be held as part of the Canterbury Residential Conference from
21 to 23 September 1989. Those interested in submitting papers should contact Dr Ian Berg, Department of Psychological Medicine (Children), The Clarendon Wing, The General Infirmary at Leeds, Belmont Grove, Leeds LS2 9NS as soon as possible.

\section{Health Policies to Combat Drug and Alcohol Problems}

\section{Consensus Statement prepared by WHO expert working group}

The above Statement was developed and agreed at a WHO Meeting on health policies to combat drug and alcohol problems. The meetings were held in Sydney and Canberra, Australia on 24-31 March 1988 and the Statement represents the consensus of experts from 12 countries drawn from all WHO Regions.

Copies of this document can be obtained by writing to the Secretary at the College. 